\title{
Skellefte mining district in 3D; results from integrated interpretation of potential field, resistivity/IP and reflection-seismic data
}

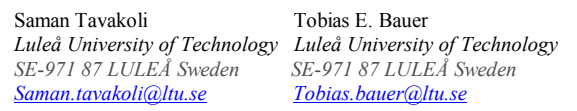

Pietari Skyttä

Luleå University of Technolog SE-971 87 LULEA Sweden pietari.skytta@ltu.se
Sten-Åke Elming

Luleå University of Technology SE-971 87 LULEA Sweden Sten-Ake.Elming@ltu.se

\section{Hans Thunehed \\ Pär Weihed}

Geovista AB

SE-97187LULEA Sweden
hans.thunehed@geovista.se
Luleå University of Technology SE-971 87 LULEA Sweden Par.Weihed@ltu.se

\section{SUMMARY}

Located in northern Sweden, the Skellefte mining district has been subject to several geological and geophysical investigations, as it is hosting abundant volcanic-hosted massive sulfide deposits. The importance of mineral exploration at greater depths in the Skellefte district has been increased since most of mineralization at shallow depths are already discovered and exploited. Therefore, geophysical methods become particularly important as they can improve our knowledge about spatial relationship between geological features at the depth. In the first part (local-scale), we used resistivity/IP data to map the subsurface geometry down to $430 \mathrm{~m}$ depth. Furthermore, the results of the resistivity/IP studies were constrained with potential field data down to $1.5 \mathrm{~km}$ depth. In the second part (Regional-scale), potential field data were used to constrain the interpretation of the reflection-seismic data down to $5 \mathrm{~km}$ depth. The result from the first part indicated a good correlation between the initial resistivity model and the magnetic and gravity field calculated from that model. The volcanosedimentary contact between the Skellefte and Vargfors group rocks and three proposed locations for sulphide mineralization were identified along the resistivity/IP profile. In second part, the gravity and magnetic data were investigated to better understand the contact between the Skellefte group, volcanic rocks and the Bothnian Basin sedimentary rocks. Furthermore the data was used to constrain the geometry of late-orogenic gabbro-diorite and granite intrusions, which occur along inferred shear zones that are only poorly indicated, or not visible at all in the reflection-seismic data. As the main outcome, the proposed integrated 3D model of the central Skellefte district (CSD) revealed crucial information about the spatial relationship between key lithologies, which will be further used to understand the evolution of CSD in the $4^{\text {th }}$ dimension, time.

Key words: Skellefte district, 3D modelling, potential field data, resistivity/ IP data

\section{INTRODUCTION}

The Skellefte district with more than 80 volcanic-hosted massive sulfide (VMS) deposits is one of the most important mining districts in the Europe (Fig 1). Base metals including $\mathrm{Zn}, \mathrm{Cu}, \mathrm{Pb}, \mathrm{Ag}$ and $\mathrm{Au}$ are currently produced from four active VMS deposits (c.f. Kathol and Weihed, 2005). However, as earlier mining activities were mainly concentrated to shallow depths, geological 3D and 4D (Time scale) modelling of the subsurface at the greater depths can provide important information for exploration and for a better understanding of the geometry and geological evolution of the district (Bauer, 2010). To achieve this, the multidisciplinary VINNOVA 4D project consisting of multiple geological and geophysical methods commenced in August 2008.

The geological investigations in the project comprise field and drill-hole observations, with the focus being in semi-regionalscale structural analysis and 3D-modelling. The geophysical techniques which contribute to the construction of the 4D model of CSD include potential field, geoelectrical, reflectionseismic and magnetotelluric (MT) data of which the first three methods are incorporated in the present study.

\section{METHOD AND RESULTS}

Two different methodologies were used for modelling in scales from local to regional. In local-scale, we conducted a field campaign to measure resistivity and IP response along two profiles with a total length of $12.4 \mathrm{~km}$ (I and II, Figs. 1 and 2). The results after inversion were constrained by magnetic $(0.5 \mathrm{~km}$ depth) and gravity data $(1.5 \mathrm{~km}$ depth $)$. In the regional-scale modelling, potential field data was used to (i) test the magnetic and gravity response of models suggested by reflection-seismic data down to a depth of $5 \mathrm{~km}$ (Dehghannejad et al, under review) and to (ii) provide information from non-reflective or poorly reflective parts of the crust. The results were then integrated into a single 3D model acting as a base for a future 4D model of the Skellefte district. 
The resistivity/ IP data collected along the two profiles in the central Skellefte district delivered essential information about key lithological contacts at depth down to $430 \mathrm{~m}$, particularly where the profiles crosses structures with a high resistivity contrast. These data were then further constrained by magnetic and gravity data to construct a local-scale model of the CSD down to a depth of $1.5 \mathrm{~km}$. In the regional-scale modelling, the gravity and magnetic response of models based on data from the three reflection-seismic profiles (acquired during 2009-2010; Dehghannejad et al, under review) were calculated. The interactive modelling of the potential field data together with reflection-seismic data were used to construct a regional 3D model of CSD. The results of local and regional-scale studies are then integrated into a single 3D model of CSD which is a base for the 4D modelling project.

\section{Local-scale modelling; electrical and potential field data}

In profile (I) (Fig. 2a), three conductive zones at $\sim 50-400 \mathrm{~m}$ depths suggest similar petrophysical characteristic as for a sulphide mineralization or for graphitic shales among which one is located close to the Norrliden N deposit (Tavakoli et al, a). In the southern part of Profile I, the contact between Skellefte group and Vargfors basin is dipping towards the north (At $\sim 6 \mathrm{~km}$, Fig. 2a). Within the sedimentary succession, the contact between turbidites and conglomerates is also wellindicated by the higher resistivity of conglomerates with respect to the turbidites (From $6 \mathrm{~km}$ to the end, Fig. 2a).

The rocks along the $5.6 \mathrm{~km}$ long northern resistivity profile (Profile II) (Fig. 2b) start with a turbiditic unit in the south and then continues into unspecified sediments. However, a zone with a high-resistive signature in the southern beginning of profile (II) may indicate that the unspecified sediments are underlain by conglomerate units located rather close to the surface (At $1 \mathrm{~km}$ beginning of profile II, Fig. 2b). In the northern part of profile (II), we suggested a south-dipping contact separating the felsic volcanic rocks of the Skellefte group from sedimentary rocks of the Vargfors group. This indicates a synclinal form for the Vargfors basin. Further to the north, the contact between the Jörn intrusive complex and Skellefte group rocks is well indicated in the resistivity/ IP data Sections of profile (II), suggesting a north-dipping contact (At $\sim 4 \mathrm{~km}$, Fig, 2b).

Regional-scale modelling; reflection-seismic and potential field data

Data from three nearly parallel reflection-seismic profiles, $\mathrm{C}_{1}$, $\mathrm{C}_{2}$ and $\mathrm{C}_{3}$ were previously acquired during 2009-2010 in the central part of the Skellefte district (Figs. 1 and 3). These profiles, each $\sim 32 \mathrm{~km}$ long, are located $\sim 3-7 \mathrm{~km}$ apart from each other, and designed such that they cross-cut the major geological structures perpendicularly. In order to understand the geometry of the Skellefte district at a greater depth $(5 \mathrm{~km})$ in a regional scale, we used potential field data to constrain the interpretation of the reflection-seismic data. The use of potential field data particularly improved the modelling in the none-reflective parts of the three profiles (Tavakoli et al, b). In areas with strong reflectors, the interpretations were wellconstrained by the model based on the gravity and magnetic data (Fig 3).

A series of south-dipping reflections observed in the southern part of profile $C_{1}$, were repeated on $C_{3}$ as well, providing a well-constrained model for shear-zone contacts. Potential field data suggest $\mathrm{a} \sim 3.5 \mathrm{~km}$ depth for the TIB gabbro-diorite intrustion. The central part of profile $\mathrm{C}_{1}$ coincides with the resistivity profile (I), which provides detailed information from the upper part of the model. Results from this part of the study also provide information of orientation of the major shear zones and rock contacts in the southern parts of the profiles $\mathrm{C}_{1}$ and $\mathrm{C}_{3}$, including rhyolite-sandstone, rhyolitegabbro, granite-gabbro and sandstone-gabbro contacts, which dip southwards and continue at depths down to $\sim 3-5 \mathrm{~km}$.

\section{CONCLUSIONS}

The joint interpretation of the multiple geophysical techniques, including resistivity/IP, magnetic, gravity, and reflection-seismic data resulted in a new image of the geometry and depth extension of important lithological units in the central Skellefte district.

The local-scale modelling of the CSD using geoelectrical and potential field data provided crucial information from shallow depths, down to $430 \mathrm{~m}$. The integration of magnetic and gravity data with the data from resistivity/IP profiles not only constrained the initial model based on electrical data, but also extended the model down to $1.5 \mathrm{~km}$. The synformal shape of the Vargfors Basin, the base of which is modelled at $700 \mathrm{~m}$ depth in its deepest part, is indicated in the result. The geometry and dip for the contact between the Jörn intrusive complex and volcanic rocks of the Skellefte group is given in the model as well, suggesting intercalation of tonalitic rocks within the Jörn-Skellefte contact. Three highly conductive zones, which are interpreted as possible sulphide mineralization, were detected and can be drilled for verification.

The regional scale model of the CSD provides valuable information from deeper parts of the crust of the central Skellefte district ( $\sim \mathrm{km}$ depth). Reflection-seismic data from the three profiles could alone not solve the model unambiguity in the major parts of the profiles, since week reflectors or none-reflective parts were not easy to correlate with the geological structures. However, the interactive interpretation of gravity and magnetic data improved the model in these areas.

The result of this study will be integrated with other geological and geophysical data, to create the 3D solid model of the CSD, which is a base for the VINNOVA 4D project. 


\section{ACKNOWLEDGMENTS}

The present work is part of the VINNOVA 4-D modeling project, which is financed by VINNOVA and Boliden Mineral AB. All members of the 4D-modelling workgroup are acknowledged for contributions and comments.

We want to thank Geovista AB and the Geological Survey of Sweden (SGU) for provision of the data and their contributions to this work.

\section{REFERENCES}

Bauer, T., 2010. Structural and Sedimentological Reconstruction of the Inverted Vargfors Basin - A base for 4D-modelling. Licentiate thesis, Luleå University of Technology, Sweden, 44 pp.

Bauer, T., Skyttä, P., Allen, RL., Weihed, P., under review. Syn-extensional faulting controlling structural inversion at the Svecokarelian Craton margin- Insights from the Palaeoproterozoic Vargfors basin, Skellefte mining district, Sweden
Dehghannejad, M., Bauer, T., Malehmir, A., Juhlin, C., Weihed, P. Crustal geometry of the central Skellefte district, northern Sweden constraints from reflection seismic investigations. Submitted to Tectonophysics.

Kathol, B \& Weihed, P., 2005. Description of regional geologic and geophysical maps of the Skellefte district and surrounding areas, $197 \mathrm{pp}$, Sveriges geologiska undersökning, Uppsala, Sweden.

Tavakoli, S., Elming, S-Å., Thunehed, H, a. 3D Modelling of the Central Skellefte district, Northern Sweden; An Integrated Model based on the electrical, potential field and petrophysical data. To be submitted to Applied Geophysics.

Tavakoli, S., Bauer, T., Elming, S-Å., Thunehed, H., Weihed, $\mathrm{P}, \mathrm{b}$. Regional scale $3 \mathrm{D}$ joint modeling of the gravity and magnetic data in the central Skellefte district; a model based on interpretation of reflection-seismic data. To be submitted to Applied Geophysics

Weihed, P., 2010, Palaeoproterozoic mineralized volcanic arc systems and tectonic evolution of the Fennoscandian shield: Skellefte district Sweden. GFF 132 (1), 83-91.

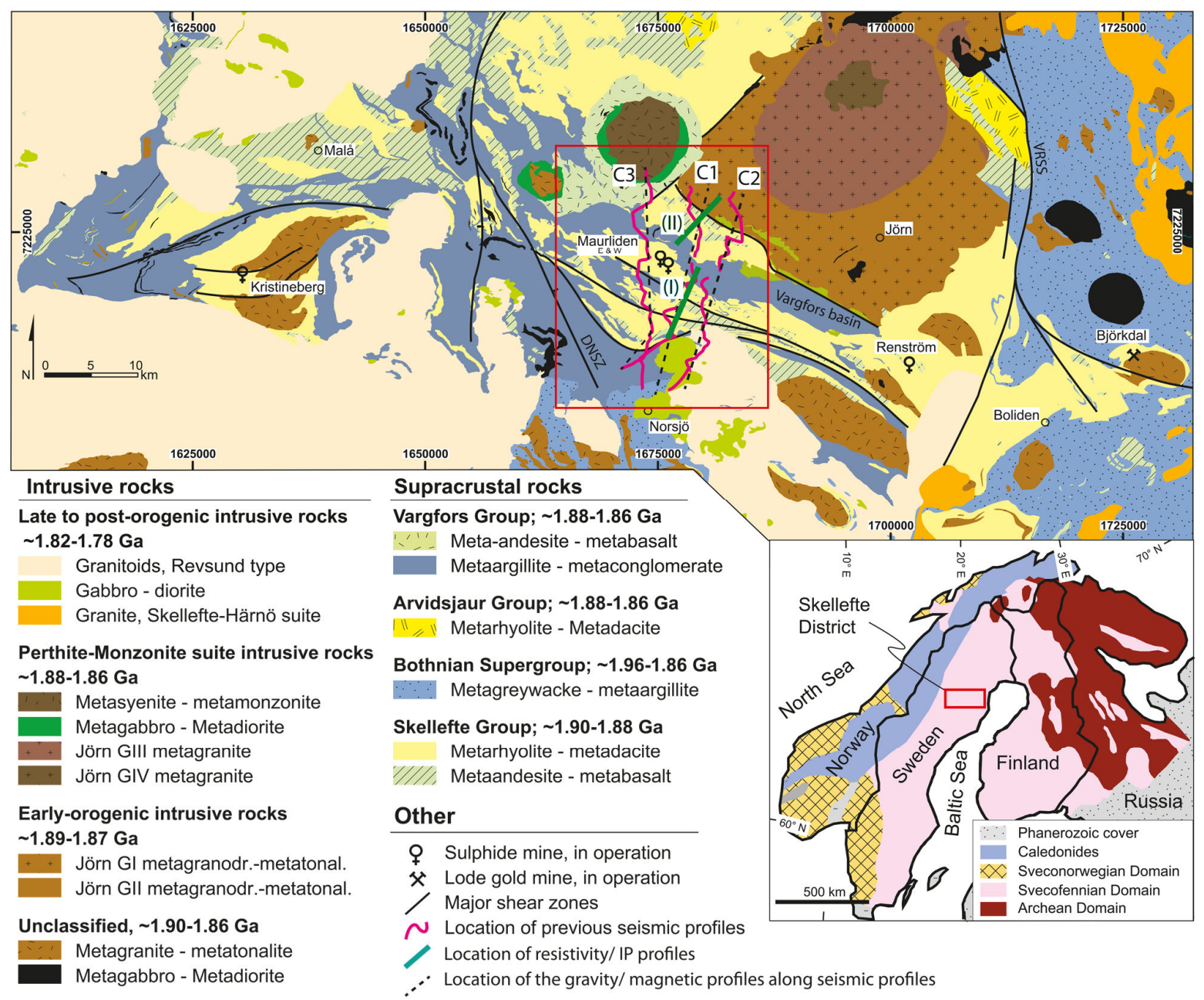

Figure 1. Geological map of the central Skellefte district with the location of stacked profiles and CDP-lines of Dehghannejad et al. (under review). Modified after Bauer (2010). 
a) Southern profile (Profile I)

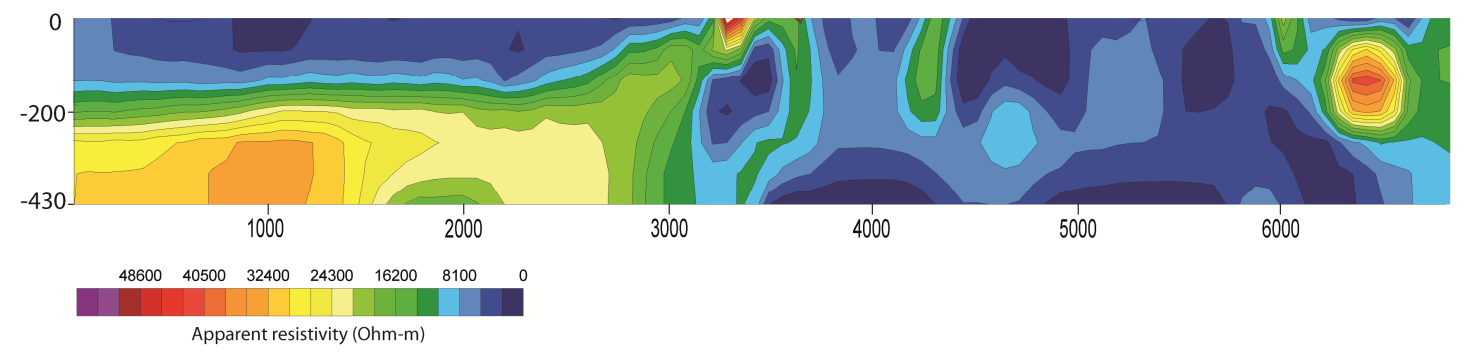

b) Northern profile (Profile II)

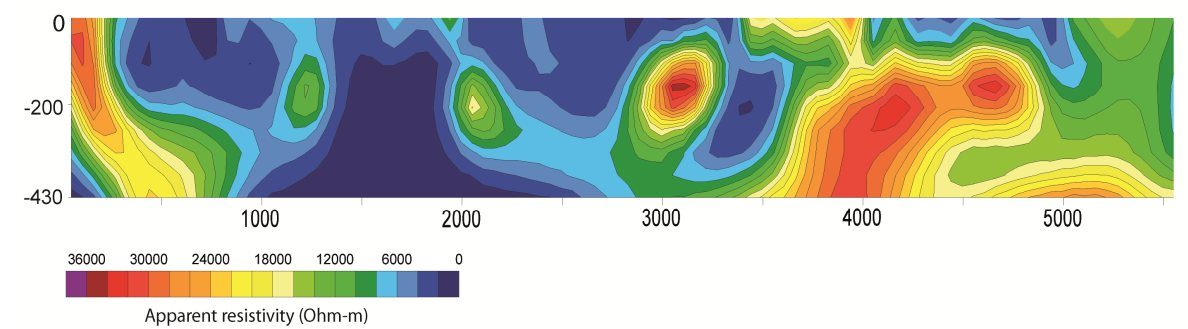

Figure 2. (a) Southern resistivity profile (Profile I) (b) northern resistivity profile (Profile II).

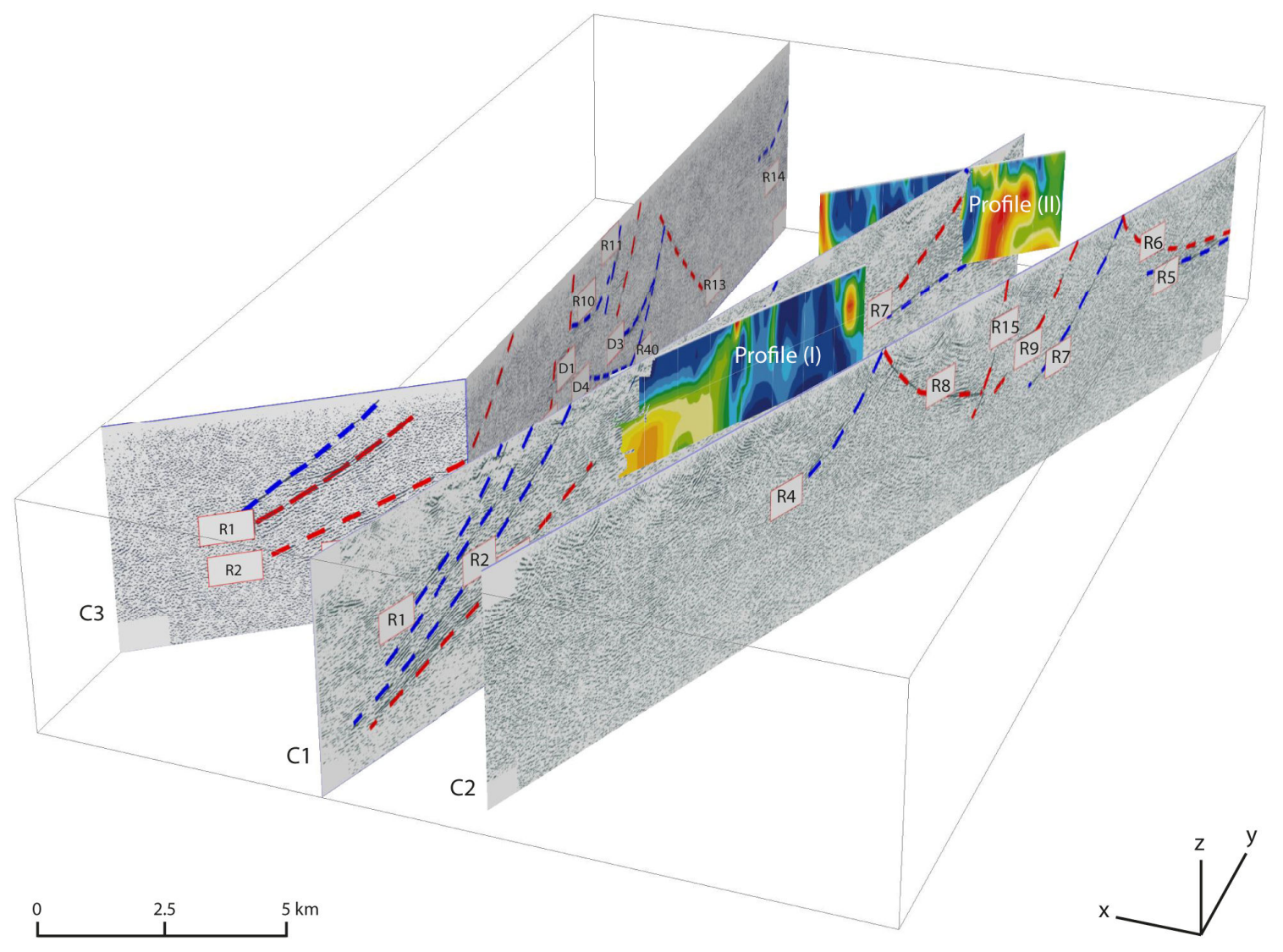

Figure 3. Integration of the three reflection-seismic profiles, $C_{1}, C_{2}$, and $C_{3}$ down to $5 \mathrm{~km}$ depth with the two resistivity depth sections, profiles (I) and (II) down to $430 \mathrm{~m}$. The resistivity sections have depth exaggeration 5 times. 